\title{
REFORMA ADMINISTRATIVA DA SECRETARIA ESTADUAL DE EDUCAÇÃO DE SÃO PAULO (2011), PROGRAMA ENSINO INTEGRAL (2012): administração pública gerencial em processo
}

\author{
Pedro Ganzeli 1
}

\section{RESUMO}

Este artigo tem por objetivo analisar as principais características da reforma administrativa da Secretaria Estadual de Educação de São Paulo (2011) e seus desdobramentos no Programa Ensino Integral (2012). Fundamentados no campo da política educacional, utilizamos como procedimento metodológico a análise documental da legislação e publicações oficiais relacionadas. As mudanças promoveram a acentuação da centralização na tomada de decisão, fomentando a difusão da cultura gerencial nos procedimentos de organização e gestão no âmbito da rede estadual de ensino.

Palavras-chave: Secretaria Estadual de Educação de São Paulo. Administração Pública Gerencial. Programa Ensino Integral.

\section{ADMINISTRATIVE REFORM OF THE STATE SECRETARIAT OF EDUCATION OF SÃO} PAULO (2011), INTEGRAL EDUCATION PROGRAM (2012): public administration in process

\begin{abstract}
This article aims to analyze the main characteristics of the administrative reform of the State Department of Education of São Paulo (2011) and its developments in the Integral Teaching Program (2012). Grounded in the field of educational policy, we use as a methodological procedure the documentary analysis of legislation and related official publications. The changes promoted the emphasis on centralization in decision making, emphasizing the managerial culture in the organization and management procedures within the state education network.
\end{abstract}

Keywords: State Secretariat of Education of São Paulo. Public Management. Integral Teaching Program.

\footnotetext{
1 Doutorado em Educação pela Universidade Estadual de Campinas (2000). Professor Livre Docente da Faculdade de Educação da Universidade Estadual de Campinas/SP/Brasil. ORCID iD: https://orcid.org/0000-0002-6237-5110. E-mail: pedro.ganzeli@gmail.com
} 


\section{REFORMA ADMINISTRATIVA DE LA SECRETARÍA ESTATAL DE EDUCACIÓN DE SÃO PAULO (2011), PROGRAMA ENSEÑANZA INTEGRAL (2012): administración pública gerencial en proceso}

\section{RESUMEN}

Este artículo tiene por objetivo analizar las principales características de la reforma administrativa de la Secretaría Estatal de Educación de São Paulo (2011) y sus desdoblamientos en el Programa Enseñanza Integral (2012). Fundamentados en el campo de la política educativa, utilizamos como procedimiento metodológico el análisis documental de las legislaciones y publicaciones oficiales relacionadas. Los cambios promovieron la acentuación de la centralización en la toma de decisiones, promoviendo la difusión de la cultura gerencial en los procedimientos de organización y gestión en el ámbito de la red estadual de enseñanza.

Palabras clave: Secretaría Estatal de Educación de São Paulo. Administración Pública Gerencial. Programa de Enseñanza Integral.

\section{INTRODUÇÃO}

A Constituição da República Federativa do Brasil, de 05 de outubro de 1988, garantiu a educação como direito social (BRASIL, 1988, Art. 6) para todos os cidadãos e definiu, entre outros, o princípio da gestão democrática do ensino público (BRASIL, 1988, Art. 206). Os postulados constitucionais apresentam-se como determinantes para a construção de uma sociedade livre, justa, solidária, garantia do desenvolvimento nacional, erradicação da pobreza e da marginalização com a redução das desigualdades sociais e regionais, promovendo $\mathrm{o}$ bem de todos, sem qualquer forma de discriminação individual ou social (BRASIL, 1988, Art. 3, Inciso I, II, III e IV).

Logo após a promulgação da Constituição Cidadã, como ficou conhecida, verificamos um período de reação conservadora, caracterizado pela investida das elites econômicas, contrárias aos processos de elaboração e implementação de políticas sociais, com a promoção da reforma do estado, assim como a recusa à reestruturação do orçamento público para o atendimento aos direitos assegurados constitucionalmente (FAGNANI, 1997).

No primeiro mandato do presidente Fernando Henrique Cardoso (19951998), do Partido da Social Democracia Brasileira (PSDB), foi criado o 
Ministério da Administração Pública e Reforma do Estado (MARE), dirigido por Luiz Carlos Bresser Pereira, que promoveu profundas mudanças na organização do aparelho de estado, por meio de alterações constitucionais, tais como a Emenda Constitucional n 19/1998, que, entre outras alterações, determinou o fim do Regime Jurídico Único na contratação de servidores da União, flexibilizando os processos de contratação de servidores públicos².

A reforma do Estado seguiu o modelo da administração pública gerencial e possuía as seguintes características:

(...) orientada para o cidadão e para a obtenção de resultados; pressupõe que os políticos e os funcionários públicos são merecedores de grau limitado de confiança; como estratégia, servese da descentralização e do incentivo à criatividade e à inovação; e utiliza o contrato de gestão como instrumento de controle dos gestores públicos (PEREIRA, 1999, p.28).

Para Abruccio (2007) os efeitos da reforma do Estado no Brasil devem ser relativizados, pois, ainda encontramos características burocráticas e patrimonialistas na administração pública.

Os preceitos da administração pública gerencial estiveram presentes nas reformas implementadas no âmbito dos entes federados, em especial na área da educação.

A Emenda Constitucional $N^{\circ} 14$, de 12 de setembro de 1996, ao criar o Fundo de Desenvolvimento do Ensino Fundamental e de Valorização do Magistério (FUNDEF) promoveu a descentralização com responsabilização crescente dos municípios no atendimento do ensino fundamental (PINTO, 2007).

Ações como a extinção das últimas classes de pré-escola na rede estadual, incentivo aos municípios no estabelecimento de convênio com o estado para a transferência de escolas e matrículas do ensino fundamental, resistência na permanência do funcionamento de escolas rurais isoladas, bem como na não matrícula de menores de 6,5 anos na rede de escolas

\footnotetext{
2 No ano de 2007, após ação direta de inconstitucionalidade, o Supremo Tribunal Federal suspendeu parte da Emenda 19, retomando a obrigatoriedade do Regime Jurídico Único na contratação de servidores da União.
}

Revista Exitus, Santarém/PA, Vol.9, №3, p. 33 - 58, JUL/SET 2019. 
estaduais, obrigaram a mobilização dos municípios no atendimento desses estudantes, intensificando o processo de municipalização da matrícula do ensino fundamental (OLIVEIRA; GANZELI, 2001).

Uma peculiaridade do estado de São Paulo é a presença do Partido da Social Democracia Brasileira (PSDB) à frente do governo estadual no período de 23 anos consecutivos (1995 a 2018), proporcionando a cont invidade das reformas gerenciais no âmbito do aparelho do estado.

A professora Roserley Neubaver da Silva, no início de sua gestão (19952013), à frente da Secretaria Estadual de Educação de São Paulo (SEE/SP), diagnosticou como sendo um dos principais entraves da educação paulista, a ineficácia e a ineficiência do sistema de ensino, indicando como principais problemas: o gigantismo da máquina burocrática, excessivo centralismo, alto índice de evasão e reprovação (chegando a 30\%) e a "ausência de mecanismos de avaliação e controle do serviço prestado". (SILVA, 1997, p.4) Para a gestora, era urgente a realização de reformas na Secretaria Estadual de Educação com a implantação de novos padrões de gestão orientados para a desconcentração e descentralização das decisões e atividades educacionais, tendo a unidade escolar como foco da gestão (SILVA, 1997).

Conforme estudo de Adrião (2006), as reformas educacionais iniciadas no ano de 1995, na rede estadual de educação foram orientadas por três diretrizes:

Primeira diretriz: reforma e racionalização da rede administrativa, o que compreendeu a transformação da estrutura administrativa da Secretaria Estadual de Educação com a implementação de duas estratégias principais: informatização dos dados educacionais, com o cadastro único de todos os estudantes do estado de São Paulo; e a Reorganização das Unidades Escolares da rede estadual de ensino, com a separação dos estudantes em unidades distintas do ensino fundamental, $1^{a}$ a $4^{a}$ séries (anos iniciais) e $5^{a}$ a $8^{a}$ séries (anos finais), mobilizando no ano de 1996 um total de $67 \%$ de unidades escolares, favorecendo a transferência dos anos iniciais para os municípios.

Segunda diretriz: desconcentração e descentralização de recursos e competências, traduzidos como enxugamento da máquina administrativa, 
com a eliminação das Divisões Regionais de Ensino, assim como a transferência para as unidades escolares de novas atribuições administrativas.

Terceira diretriz: mudanças no padrão de gestão - racionalização do fluxo escolar; aumento da autonomia administrativa, pedagógica e financeira da unidade escolar; e instituição de mecanismos de avaliação dos resultados escolares.

O conjunto de reformas educacionais teve como objetivo principal a diminuição dos serviços oferecidos pelo governo estadual, com a transferência de escolas para os municípios, bem como ampliar a capacidade de controle dos órgãos centrais da Secretaria da Educação, considerando a avaliação de resultados como um elemento fundante na nova dinâmica organizacional da rede estadual de ensino.

A lógica gerencial na administração da educação paulista foi sendo reforçada, ao longo dos anos de governo do PSDB, com a edição de grande número de normativas que promoveram a responsabilização dos docentes no processo de melhoria da qualidade do ensino.

Entre essas normativas disciplinadoras destaca-se a Lei Complementar $\mathrm{n}^{\circ}$ 1.078, de 17 de dezembro de 2008, que instituiu a Bonificação por Resultados para os servidores da Secretaria da Educação. Os gestores, docentes e funcionários das unidades escolares que atingissem as metas determinadas pelo Secretário da Educação (Art. 7) receberiam um bônus financeiro.

Para Heloani e Piolli (2012), a política de responsabilização das esferas descentralizadas da educação, promoveu a desvalorização do caráter humano do trabalho docente que passou a ser orientado pela determinação da métrica de metas quantitativas:

A ciência da gestão quer explicar o real e o conjunto das relações sociais mediante a modelagem matemática, produzindo indicadores, estatísticas e rankings e todo um conjunto de prescrições normativas voltadas para 0 desempenho e a performance" (p. 35). 
Para Adrião (2006) as alterações na gestão da educação paulista tiveram como objetivo mudanças no padrão de gestão que,

(...) articulou mecanismos que descentralizavam a gestão de recursos financeiros e materiais, ao mesmo tempo em que se centralizavam a definição dos objetivos escolares e o controle sobre a organização do cotidiano escolar (p. 174-5).

Em que pesem as alterações implementadas na rede de ensino, os órgãos de administração central mantiveram a estrutura organizacional, cuja última reforma ocorreu no ano de 1976, demandando uma nova modelagem institucional da SEE/SP Educação (SÃO PAULO, 2013).

Buscando compreender o significado das mudanças mais recentes na organização da educação paulista, este artigo tem por objetivo analisar as principais características da reforma administrativa da Secretaria Estadual de Educação de São Paulo (2011) e seus desdobramentos no Programa Ensino Integral (2012), considerado como um modelo de organização gerencial na educação.

Fundamentado no campo da política educacional (AZEVEDO, 1997), este estudo possui caráter exploratório, com a utilização dos seguintes procedimentos metodológicos: a análise documental da legislação e publicações oficiais relacionadas ao tema (SHIROMA; CAMPOS, GARCIA, 2005).

Apresentaremos, inicialmente, as principais características da reforma administrativa ocorrida em 2011 na Secretaria Estadual de Educação que teve como princípio a gestão por resultados, para em seguida, analisarmos as características básicas do "Programa Ensino Integral" 3, instituído em 2012, buscando compreender as suas congruências com as mudanças gerencias processadas em nível central.

\footnotetext{
3 A Lei Complementar n 1.164/2012 registra o termo "Programa Ensino Integral", entretanto verificamos outras formas para a denominação do Programa, tais como: "Novo Programa Ensino Integral" ou "Novo Modelo de Ensino Integral", neste artigo utilizaremos a expressão da Lei.
} 


\section{REORDENAMENTO DA ESTRUTURA ADMINISTRATIVA DA SECRETARIA DA EDUCAÇÃO: gestão por resultados com foco no aluno}

O estado de São Paulo ocupa uma área de 248.808,8 $\mathrm{km}^{2}$, sendo constituído por 645 municípios. No ano de 2015, sua população foi estimada em 44.396.484 habitantes e sua economia representou $28,7 \%$ do PIB nacional4.

Na área da educação, verificamos, no período compreendido entre os anos de 1996 a 2014, a transferência de matrículas do ensino fundamental, da rede estadual, para as redes municipais. Em 1996, a rede estadual abrigava nos anos iniciais do ensino fundamental 2.267.948 matrículas, reduzindo para 649.734 matrículas no ano de 2014. Nas redes municipais, verificamos o movimento inverso, quando em 1996 atendia 421.917 estudantes nos anos iniciais do ensino fundamental, ampliando para 1.714 .980 matrículas em $2014^{5}$.

Nos anos finais do ensino fundamental, a rede estadual comportava 2.450.591 matrículas no ano de 1996, passando para 1.499.788 matrículas no ano de 2014, enquanto que o atendimento nas redes municipais passou de 304.787 matrículas no ano de 1996, para 640.513 matrículas no ano de 2014.

No ensino médio a rede estadual de ensino participou de forma mais constante na oferta de matrículas, com 1.352 .696 estudantes no ano de 1996, para 1.644 .362 estudantes no ano de 2014. Neste ano, as redes municipais atendiam 23.827 estudantes 6.

Esses dados evidenciam os impactos das reformas educacionais de descentralização, realizadas ao longo do período.

Considerando que o modelo gerencial se tornou hegemônico nos processos de reconfiguração da administração pública, apresentaremos suas principais características, buscando favorecer a nossa compreensão sobre as alterações organizacionais da SEE/SP.

\footnotetext{
4 Disponível em: <http://goo.gl/8QiaUz>, acesso em: 19 fev. 2016. IBGE Estados disponível em: <http://goo.gl/ht9roK>, acesso em: 19 fev. 2016.

5 Disponível em:<http://goo.gl/LN4FLs>, acesso em: 30 mar. 2016. Callegari (2010).

6 Disponível em http://www.imp.seade.gov.br/frontend/\#/tabelas, acesso em: 30 mar. 2016.
} 
A administração pública gerencial tem por base a incrementação de processos de gerencialismo e gerencialização. Para Newman e Clarke (2012) o gerencialismo, mais do que um conjunto de técnicas de administração é um processo de mudanças culturais, com a introdução de novas lógicas de tomada de decisões que privilegiam a eficiência econômica em detrimento de outros valores públicos. Como ideologia, o gerencialismo reproduz na administração pública o ethos de negócios do setor privado, priorizando o desempenho à imagem do mercado competitivo.

A gerencialização deve ser considerada como

um processo de estabelecimento de autoridade gerencial sobre os recursos corporativos (materiais, humanos e simbólicos) e tomada de decisão corporativa. Em segundo lugar, a generalização é um processo de estabelecimento de estruturas calculistas de gerencialismo. Estas definem os termos e as condições da tomada de decisão. O objetivo da gerencialização é incorporar estas estruturas como as formas de conhecimento que governam padrões de relacionamentos internos e externos. Finalmente, a generalização é um processo de criação de formas de 'gerir' e tipos de gestores (NEWMAN; CLARKE, 2012, p 359 - grifo dos autores).

Ao analisar as reformas no setor público no Reino Unido nos anos de 1980 e 1990, os autores verificaram o aumento substancial no número de pessoas empregadas como gestores. Esse movimento ocorreu com a contratação de funcionários importados ou convertidos:

os primeiros vieram de algum outro lugar; os últimos eram produzidos na casa por meio de programas de treinamento ou desenvolvimento em gestão e estavam fazendo uma mudança na carreira rumo a um papel claramente identificado como gerencial (em um contexto onde as carreiras organizacionais eram cada vez mais definidas em termos gerenciais em vez de profissionais) (NEWMAN; CLARKE, 2012, $\mathrm{p}$ 360 - grifo dos autores).

A gestão por resultados, enquanto referência do modelo gerencial, tem como característica principal a adoção de metas de desempenho para a orientação das políticas públicas, com a utilização de mecanismos de contratualização e aferição de desempenho, utilizados para a responsabilização dos agentes envolvidos. No Brasil, na área da educação, 
a avaliação externa, a remuneração por desempenho e currículo, foram mecanismos comuns na implementação do modelo (SEGATTO; ABRUCIO, 2017).

O conjunto de processos que envolvem o gerencialismo e a gerencialização buscam a reconstrução do Estado, promovendo alterações nas estruturas de definição de políticas, orientadas para o direito de gerir, considerado necessário para o alcance da eficiência na administração pública.

A Secretaria de Educação do Estado de São Paulo no período de 1976 a 2010 compreendia a seguinte estrutura administrativa:

Figura 1 - Organograma Secretaria da Educação 1976-2010

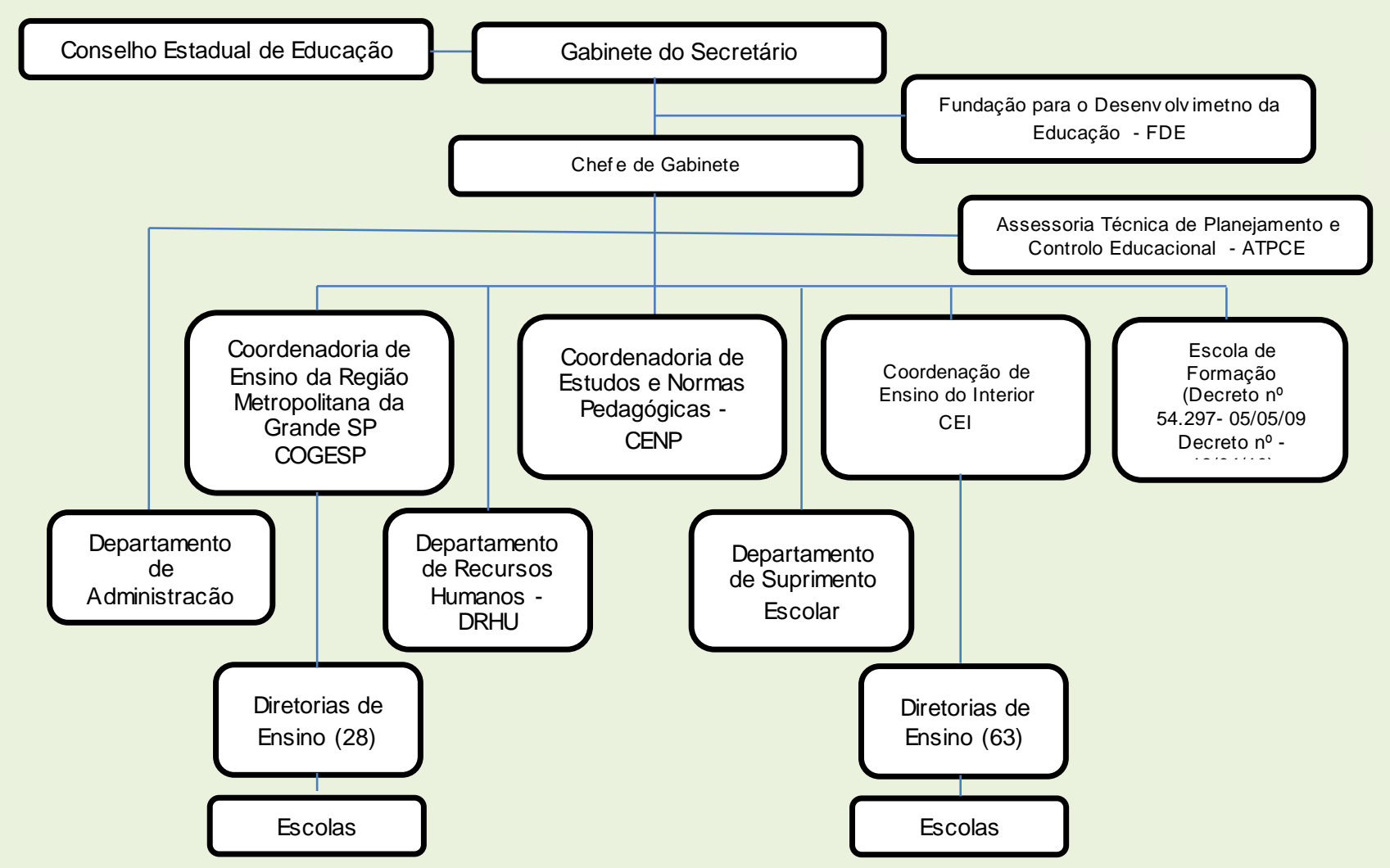

Fonte: São Paulo (2013).

Entre outros órgãos de gestão, destacamos duas coordenadorias de abrangências regionais: a Coordenadoria de Ensino da Grande São Paulo (COGESP) e a Coordenadoria de Ensino do Interior (CEI) e dois outros órgãos 
centralizados de planejamento e currículo, respectivamente: Assessoria Técnica de Planejamento e Controle Educacional (ATPCE) e a Coordenadoria de Ensino e Normas Pedagógicas (CENP). Essa estrutura passou a ser questionada pelos dirigentes, pois não estava adequada às políticas educacionais implementadas com o início do governo do PSDB no estado, conforme apresentamos anteriormente.

Os estudos para a reforma da estrutura administrativa da Secretaria da Educação tiveram início no ano de 2008, sendo esses, realizados pela Fundação do Desenvolvimento Administrativo do Estado de São Paulo FUNDAP, com a intenção de modernizar o desenho organizacional da pasta (SÃO PAULO, 2013).

Em julho de 2011 com a publicação do Decreto $n^{\circ} 57.141$, foi iniciada a reorganização da Secretaria da Educação, tendo como princípios, entre outros, gestão por resultados com foco no aluno (Art. $3^{\circ}$, incisos I e III).

modelo de gestão por resultado implementado separou de forma clara e objetiva os órgãos destinados à elaboração das políticas educacionais daqueles que se responsabilizaram pela execução das ações:

A natureza da atuação obedece a quatro vetores. É centralizada ao
definir políticas e metas educacionais, ao propor o conteúdo
educacional, organizar o ano letivo, definir política, diretrizes e
normas, aplicar e gerir recursos. Mas é descentralizada na execução
do ensino e aprendizagem, na aplicação e gerenciamento dos
recursos locais. É articulada na definição de prioridades, estratégias e
políticas, na gestão de recursos e na realização de políticas, e,
finalmente, é de responsabilidade comum para a obtenção dos
resultados e metas da educação e monitoramento e avaliação de
tais resultados (SÃO PAULO, 2013, p.15-grifo no original).

A gestão por resultados compreende a responsabilização de órgãos e servidores pela "entrega" de produtos definidos e formatados pelas esferas centrais da organização:

A visão de resultados, neste caso, se baseia em entregas que precisam ser realizadas em todas as unidades da estrutura, a partir do seu ponto mais importante - a sala de aula. No outro extremo, onde está a estrutura central da Secretaria, se encontram a 'inteligência' e o monitoramento da educação. Essas unidades centrais têm responsabilidades claras de entregas para a rede, sem 
dispersão e duplicidade de esforços, recursos e comandos (SÃO PAULO, 2013, p.14).

A reforma reforçou o caráter centralizador na tomada de decisões, privilegiando as relações entre lideranças e liderados na perspectiva da eficiência e efetividade dos processos administrativos.

A Secretaria de Educação passou a ter a seguinte estrutura administrativa, conforme o Decreto $n^{\circ} 57.141$, em seu artigo $4^{\circ}$ :

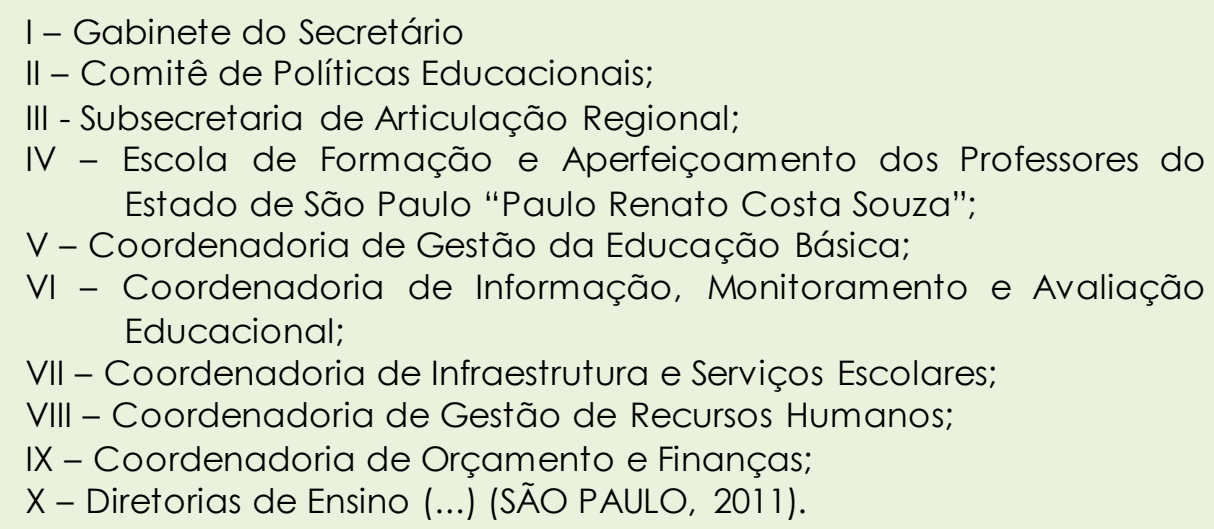

Figura 2 - Organograma da Secretaria de Educação - 2011

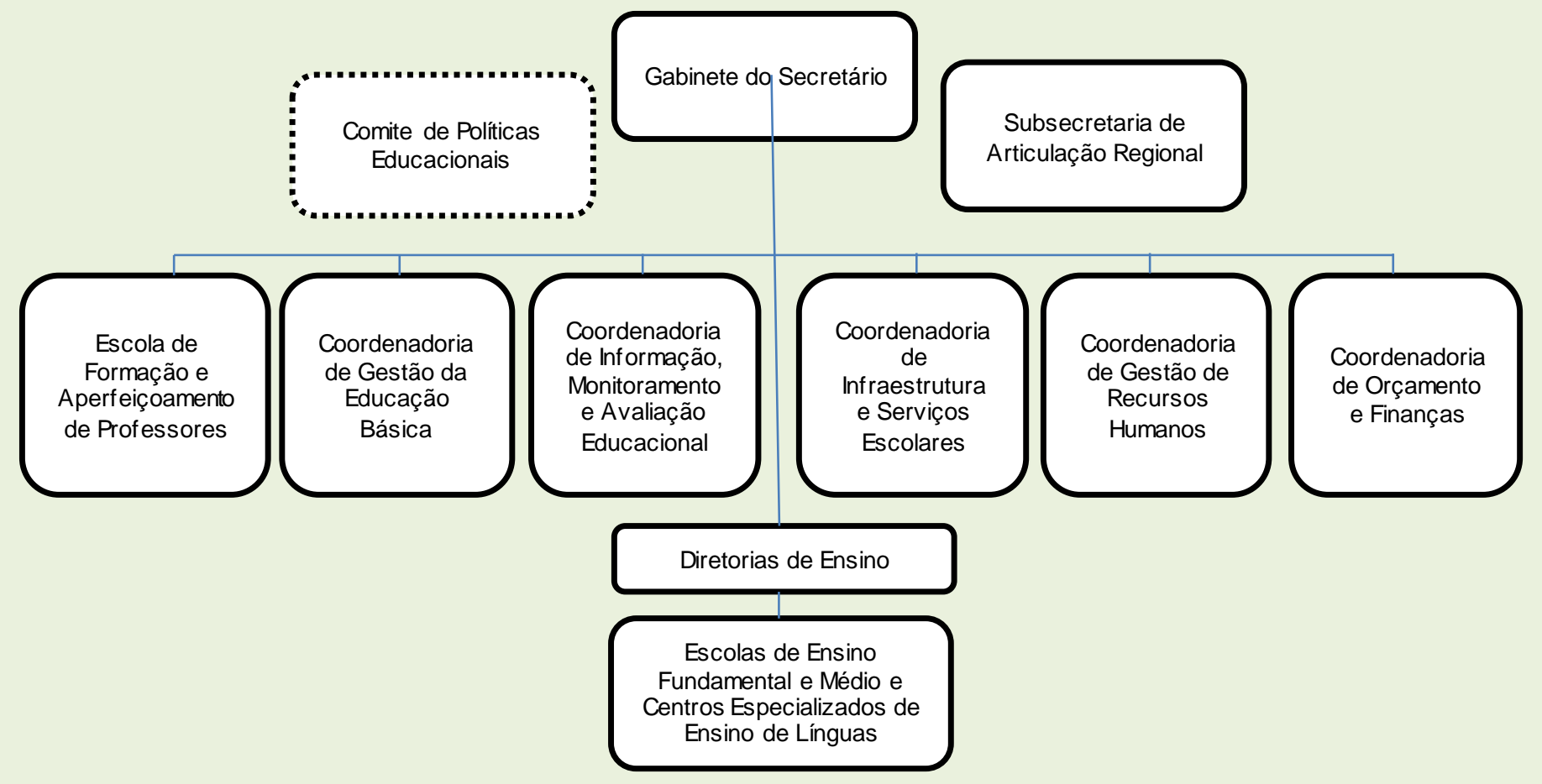

Fonte: São Paulo (2013).

Na relação hierárquica entre as diferentes instâncias que compõem a estrutura administrativa da Secretaria de Educação, destacam-se o Comitê 
de Políticas Educacionais e a Escola de Formação e Aperfeiçoamento dos Professores.

O Comitê de Políticas Educacionais, composto pelos dirigentes das coordenadorias e da Escola de Formação, passou a ser o responsável pela "definição da política educacional e das estratégias a serem implementadas pelas unidades centrais, regionais e locais da Secretaria de Educação" (SÃO PAULO, 2011, art. 11). Figura-se assim, um colegiado do corpo de gestores dos órgãos centralizados como definidor da política educacional em toda a extensão da educação paulista.

$\mathrm{Na}$ estrutura hierárquica da Secretaria, destacamos a importância adquirida pela Escola de Formação e Aperfeiçoamento (EFAP) que possui como atribuição, entre outras, a formulação de políticas de formação, de acompanhamento e de avaliação de docente e gestores.

O Decreto $n^{\circ} 57.141 / 2011$, em seu artigo 40, define as responsabilidades da EFAP:

VI - por meio do Centro de Avaliação:

a) propor a definição:

1. do perfil de competências gerais e específicas para professores das diferentes etapas, modalidades e disciplinas da educação básica da rede estadual destinado a referenciar os descritores utilizados em avaliações, concursos, provas, exames e certificações;

2. de metodologias e indicadores para avaliação da efetividade das ações educacionais de responsabilidade da Escola, em articulação com os Centros de Formação e Desenvolvimento Profissional;

b) analisar os resultados das avaliações de desempenho dos alunos da educação básica na rede estadual e os indicadores de desempenho, para subsidiar os programas de formação e aperfeiçoamento de professores e especialistas;

c) desenvolver sistemas de avaliação, em especial de aprendizado e de reação, com vista ao melhor aproveitamento dos cursos ministrados pela Escola;

d) articular-se com as demais unidades da Escola na proposição de melhorias e aperfeiçoamento dos programas educacionais, com base nas avaliações efetuadas; (...) (SÃO PAULO, 2011).

Evidenciamos nas mudanças realizadas na estrutura administrativa da Secretaria da Educação, a ampliação do controle sobre o trabalho docente, cabendo aos órgãos centrais à definição dos conteúdos e métodos, assim como as formas de avaliação da aprendizagem a serem utilizadas na rede estadual de ensino. 
Nesse sentido, verificamos semelhanças com as reformas educacionais implementadas no Reino Unido, ao não valorizarem a participação dos professores nos processos de elaboração, execução e avaliação dos programas educacionais, conforme análise de Maguire e Ball (2011), ao analisarem essas as reformas:

(...) se assemelham a nada mais do que à clássica empresa fordista com seus tradicionais sistemas de linha de montagem, suas estruturas hierárquisadas, seu processo decisório executivo e seus ambientes de trabalho microgerenciados, estes últimos remificados pelos requerimentos do Currículo Nacional (p.189).

Essas mudanças foram fundamentais para a implementação do Programa Ensino Integral que representa, a nosso ver, a materialização mais acabada da concepção da gestão por resultados com foco no aluno, conforme analisaremos no que se segue.

\section{PROGRAMA ENSINO INTEGRAL: novas formas de controle do trabalho docente}

No decorrer da gestão do PSDB no estado de São Paulo foram criados dois programas que buscaram promover o "ensino integral": "Projeto Escola de Tempo Integral" no ano de 2006 e o "Programa Ensino Integral", lançado no ano de 2012.

A Secretaria da Educação do Estado de São Paulo, por meio da Resolução SE n 89, de 09 de dezembro de 2005, instituiu o "Projeto Escola de Tempo Integral", com o objetivo de "prolongar a permanência dos alunos de ensino fundamental na escola pública estadual (...)" (SÃO PAULO, 2005, Art. $1^{\circ}$ ), caracterizando-se como um programa de ampliação da jornada escolar do estudante. Foram priorizadas as escolas que possuíam espaço físico adequado e nas regiões de baixo Índice de Desenvolvimento Humano (IDH).

Este projeto recebeu críticas, tais como: não houve alteração substancial na organização do tempo e do espaço escolar; a jornada de trabalho dos professores não garantiu a sua permanência em uma mesma unidade escolar; assim como não foi possibilitada a elaboração de uma 
proposta articulada entre os componentes curriculares (CASTRO; LOPES, $2011)$.

No ano de 2012 a Secretaria da Educação instituiu o "Programa Ensino Integral" da rede estadual de ensino de São Paulo, pela Lei Complementar $\mathrm{n}^{\circ}$ 1.164, de 4 de janeiro, sendo direcionado para as Escolas Estaduais de Ensino Médio, que, neste ano, recebeu a adesão de 16 unidades escolares em um universo de 3.978 escolas de Ensino Médio regular ${ }^{7}$. Em 28 de dezembro deste ano, a Lei Complementar $n^{\circ} 1.191$, promoveu modificações no Programa Ensino Integral, possibilitando o ingresso de escolas de Ensino Fundamental8 no mesmo.

A Secretaria de Educação informou que em 2018 o "Projeto Escola de Tempo Integral" atendeu a 48 mil estudantes, com adesão de 226 unidades escolares e o "Programa Ensino Integral" atendeu a 104 mil estudantes, com adesão de 308 unidades escolares ${ }^{9}$. Considerando que o total de matrículas da rede estadual no ano de 2018 foi de cerca de 3,5 milhões de estudantes, verificamos o baixo impacto quantitativo dos programas de ensino integral com o atendimento total de 158 mil matrículas.

O Programa Ensino Integral teve como modelo as experiências do Ginásio de Pernambuco, idealizado pelo Instituto de Corresponsabilidade pela Educação (ICE), entidade privada sem fins lucrativos, criada por um grupo de empresários com a intenção de difundir o pensamento corporativo na gestão escolar, por meio do modelo Tecnologia Empresarial Sócio Educacional, identificado pela sigla 'TESE' .

Para Krawczyk (2014), a TESE tem como objetivo a incorporação da cultura empresarial entre os jovens, conforme explicita:

A proposta pedagógica busca desenvolver uma cultura empresarial nos jovens estudantes, dotando-os de maior capacidade de resistência e adaptação a situações novas. Seu esforço e o desenvolvimento dessas capacidades permitem-lhes permanecer

\footnotetext{
7 Disponível em https://goo.gl/QLVwiz. Acesso em 04 abr. 2016

8 Analisaremos a legislação, indicando, quando necessário as alterações ocorridas.

9 Disponível em: http://www.educacao.sp.gov.br/escola-tempo-integral. Acesso em: 25 mar. 2018.
} 
com êxito na escola. Isso se materializa tanto nos objetivos da proposta pedagógica, quanto na transposição progressiva da linguagem do mundo empresarial para a escola, identificando-a com a vida na empresa e o jovem, com 0 trabalhador/empreendedor (KRAWCZYK, 2014, p. 32).

Assim, evidenciamos o caráter ideológico da TESE para a difusão do projeto societário que se caracteriza pelo individualismo, o empreendedorismo e a meritocracia, próprios do modelo neoliberal.

Entendemos ser significativo ressaltar que o foco principal da Lei Complementar $\mathrm{n}^{\circ} 1.164 / 2012$ que institucionalizou o "Programa Ensino Integral", foi a nova organização do trabalho do professor, conforme podemos observar pelo seu enunciado:

Institui o Regime de Dedicação Plena e Integral - RDPI e a Gratificação de Dedicação Plena e Integral - GDPI aos integrantes do Quadro Magistério em exercício nas Escolas Estaduais de Ensino Médio de Período Integral, e dá outras providências correlatas (SÃO PAULO, 2012a).

O Programa Ensino Integral introduziu novidades na organização do trabalho de gestores e docentes da rede estadual de ensino, ou seja, as alterações devem ser compreendidas como determinações adicionais àquelas já existentes. Assim, cabe, mesmo que de forma abreviada, analisar as bases legais que organizam o trabalho na rede estadual de ensino paulista.

O Estatuto do Magistério Paulista, Lei Complementar n 444 de 27 de dezembro de 1985, regulamentou a Jornada de Trabalho docente em três módulos: Jornada Integral de Trabalho Docente: 40 horas semanais; Jornada Completa de Trabalho Docente: 30 horas semanais; Jornada Parcial de Trabalho Docente: 16 horas semanais. Essa legislação sofreu várias alterações com o passar do tempo 10 .

A Resolução SE $n^{\circ}$ 8, de 19 de janeiro de 2012, que dispõe sobre a carga horária dos docentes da rede estadual de ensino, disciplinou em seu artigo $2^{\circ}$, a Jornada de Trabalho, com a seguinte configuração:

10 A Lei $n^{\circ} 11.738$, de 16 de julho de 2008, instituiu "piso salarial profissional nacional para os profissionais do magistério público da educação básica", gerou intenso debate sobre a adequação da jornada de trabalho docente.

Revista Exitus, Santarém/PA, Vol.9, №3, p. 33 - 58, JUL/SET 2019. 
I - Jornada Integral de Trabalho Docente:

a) 32 (trinta e duas) aulas;

b) 3 (três) aulas de trabalho pedagógico coletivo na escola;

c) 13 (treze) aulas de trabalho pedagógico em local de livre escolha; II - Jornada Básica de Trabalho Docente:

a) 24 (vinte e quatro) aulas;

b) 2 (duas) aulas de trabalho pedagógico coletivo na escola;

c) 10 (dez) aulas de trabalho pedagógico em local de livre escolha;

III - Jornada Inicial de Trabalho Docente:

a) 19 (dezenove) aulas;

b) 2 (duas) aulas de trabalho pedagógico coletivo na escola;

c) 7 (sete) aulas de trabalho pedagógico em local de livre escolha;

IV - Jornada Reduzida de Trabalho Docente:

a) 9 (nove) aulas;

b) 2 (duas) aulas de trabalho pedagógico coletivo na escola;

c) 3 (três) aulas de trabalho pedagógico em local de livre escolha (SÃO PAULO, 2012b).

Esta forma de organização do trabalho dificulta que o docente totalize a sua jornada em uma única unidade escolar. O deslocamento docente para outras escolas (rede estadual, rede municipal ou instituições privadas) gera inúmeros problemas relacionados à sua itinerância no exercício profissional.

A Lei Complementar $n^{\circ} 1.164 / 2012$ instituiu o Regime de Dedicação Plena e Integral - RDPI, com jornada de 40 horas semanais de trabalho em uma mesma unidade escolar, sendo vetado o desempenho de qualquer outra atividade, pública ou privada, durante o horário de funcionamento da escola. Foi criada a Carga Horária Multidisciplinar, exercida pelo servidor do quadro magistério exclusivamente em Escola Estadual do Programa Ensino Integral.

Para sustentar essa nova organização do trabalho no magistério público paulista, foi instituída pela Lei Complementar $n^{\circ} 1.164 / 2012$ a Gratificação de Dedicação Plena e Integral - GDPI, correspondente a 50\% (cinquenta por cento) do valor da faixa e nível da Estrutura da Escala de Vencimentos para os gestores e docentes, integrantes do Programa Ensino Integral. A Lei Complementar $n^{\circ} 1.191$, de dezembro de 2012 aumentou o percentual de gratificação para $75 \%$ (setenta e cinco por cento) da Escala de Vencimentos.

A necessidade de adoção da GDPI apresentou-se como estratégia necessária para a adesão de servidores ao Programa Ensino Integral, assim 
como o controle de sua permanência no mesmo. A legislação determinou que os gestores e docentes candidatos ao ingresso no Programa Ensino Integral, deveriam passar por seleção realizada na Diretoria de Ensino. O servidor selecionado, assume a função na Escola do Programa Ensino Integral por designação, o que permite a sua remoção a qualquer momento, caso não atenda aos princípios e diretrizes do Programa Ensino Integral, sendo submetido a avalições periódicas e específicas (SÃO PAULO, 2012c, Art. $3^{\circ}, \S 4^{\circ}$ ).

Verificamos assim, a existência de uma estrutura administrativa específica para unidades escolares integrantes do Programa Ensino Integral, com disciplinamento próprio, permitindo a flexibilização no processo de ingresso e remoção de pessoal nas escolas participantes. Essa estrutura paralela permite aos dirigentes da Secretaria da Educação o controle sobre aqueles considerados aptos ou não a ingressar e permanecer em RDPI com a GDPI, enquanto instrumentos de disciplinamento do magistério paulista em relação às suas determinações.

A Lei Complementar $n^{\circ} 1.164 / 2012$ deixa evidenciada a preocupação na responsabilização de cada servidor na propagação dos princípios do Programa Ensino Integral, conforme podemos ver nas atribuições dos servidores:

Diretor escolar:

XI - atuar como agente difusor e multiplicador do modelo pedagógico da Escola, de suas práticas educacionais e de gestão, conforme os parâmetros fixados pelos órgãos centrais da Secretaria da Educação; (Art. 4º)

Vice-Diretor:

$\checkmark$ - assumir a direção da escola nos períodos em que o Diretor estiver atuando como agente difusor e multiplicador do modelo pedagógico de Escola; (Art. $5^{\circ}$ )

Professor Coordenador Geral:

VIII - apoiar o Diretor nas atividades de difusão e multiplicação do modelo pedagógico da respectiva Escola, em suas práticas educacionais e de gestão pedagógica, conforme os parâmetros fixados pelos órgãos centrais da Secretaria da Educação; (Art. $6^{\circ}$ )

Professores:

II - organizar, planejar e executar sua tarefa institucional de forma colaborativa e cooperativa visando ao cumprimento do plano de ação da Escola; (...) 
IV - Incentivar e aprovar as atividades de protagonismo juvenil, na forma da lei; (Art.7º) (SÃO PAULO, 2012a).

O caráter centralizador da organização do trabalho docente se manifesta ao longo da Lei, demonstrando o pleno alinhamento com a reforma da estrutura administrativa implementada na Secretaria da Educação.

Cabe lembrar a existência de determinações que afetam a organização do trabalho docente da rede estadual, inclusive aos participantes do Programa Ensino Integral, determinadas de forma centralizada como, por exemplo, o Programa São Paulo Faz Escola, proposta curricular, com orientações programáticas do trabalho de professores e estudantes por disciplinas (Caderno do Professor e Caderno do Aluno), assim como o atendimento ao Sistema de Avaliação de Rendimento Escolar do Estado de São Paulo (SARESP).

Considerando que o ingresso ao Programa deve ser por adesão, podemos inferir que existe uma dinâmica de contratualização entre as partes (dirigentes/servidores), que se materializa por intermédio de diversos instrumentos de regulação, tais como aqueles utilizados para o planejamento das escolas, conforme determina a Lei Complementar $n^{\circ}$ 1.164/2012: Plano de Ação - Coordenado pelo Diretor Escolar, elaborado de forma colaborativa, contendo diagnóstico, indicadores, metas, estratégias e avaliação de resultados da unidade escolar; Programa de Ação elaborado por toda a equipe escolar com os objetivos, metas e resultados da aprendizagem a serem alcançadas pelo aluno; e o Projeto de Vida elaborado pelo aluno:

(...) que expressa as metas e define prazos, com vistas à realização das aptidões individuais, com responsabilidade individual, responsabilidade social e responsabilidade institucional em relação à Escola Estadual de Ensino Médio de Período Integral. (Art. 2, inciso VI) (SÃO PAULO, 2012a).

A esses instrumentos de planejamento somam-se outros, tais como, Plano Bimestral e Guias de Aprendizagem que devem estar alinhados e 
integrados entre si, respeitando as diretrizes e parâmetros emanados pelos órgãos centrais da Secretaria da Educação.

O caráter contratual presente nos instrumentos de planejamento do trabalho de docentes e dos estudantes representa a essência da administração pública gerencial, traduzida na responsabilização individual pelo alcance de metas definidas a partir dos órgãos centrais.

Entre os múltiplos instrumentos de regulação da ação pública, o contrato individual de desempenho ganha destaque nos processos de coordenação e cooperação na dinâmica da administração pública gerencial. Esse instrumento de regulação caracteriza-se pela convenção de acordos entre atores em uma dada organização para o alcance de resultados com a formalização de consensos e a legitimação dos procedimentos adotados.

\footnotetext{
Estes procedimentos contratuais traduzem a intenção de mobilizar os novos conhecimentos e técnicas de gestão, designadamente de produção de conhecimento como as monitorizações e as avaliações de resultados, para melhorar o funcionamento dos estabelecimentos públicos (HIPÓLITO, 2011, p.92).
}

A autonomia de professores e estudantes fica restrita ao âmbito da operacionalização de atividades delimitadas pelo complexo conjunto de instrumentos de regulação.

O Projeto de Vida a ser elaborado pelo aluno, com a tutoria de professores, por exemplo, limita-se a atender aos marcos do Programa Ensino Integral, que estipula o Protagonismo Juvenil como princípio norteador.

O "Protagonismo Juvenil" apresenta-se como a principal referência para a organização do trabalho docente, sendo definido como "processo pedagógico no qual o aluno é estimulado a atuar criativa, construtiva e solidariamente na solução de problemas reais na escola, na comunidade e na vida social" ( $L C n^{\circ} 1.191 / 2012$, artigo $2^{\circ}$, inciso VII).

Ferretti, Zibas e Tartuce (2004) afirmam que, apesar do caráter "fluido e multifacetado" do termo 'Protagonismo Juvenil', cunhado nos anos de 1920 e 1930 por educadores que passaram a valorizar a ação do estudante no 
processo educativo, como John Dewey, ele adquiriu novos significados com as transformações sociais, culturais e econômicas da sociedade pósmoderna, assentadas no século XXI, com novas demandas para a educação dos jovens.

De forma geral, o Protagonismo Juvenil se apresenta como um conceito que compreende a responsabilização dos indivíduos na resolução de problemas sociais, sua participação solidária na sociedade, aquisição de conhecimentos que favoreçam $\circ$ enfrentamento das transformações políticas, econômicas e culturais na contemporaneidade, entre outras habilidades que atendam a formação para a cidadania.

Os autores questionam a ausência de historicidade presente em estudos mais recentes sobre o Protagonismo Juvenil, quando explicam a juventude de forma homogeneizada, sem considerar as condições econômicas, culturais e sociais de jovens em diferentes sociedades, assim como em uma mesma sociedade.

Há que pensar, pois, em adolescências e juventudes. Se essa proposição faz sentido, então se pode tomá-la como uma referência importante para discutir a relação entre protagonismo e educação. O suposto é o de que, se a referência a uma juventude em geral pode ser considerada uma abstração, também o pode a referência a um protagonismo, tratado genericamente como o fazem os autores em pauta, tendo em vista sociedades também genéricas e abstratas. Abordagens genéricas e abstratas, por não se ancorarem em materialidades históricas, podem facilmente descambar para idealizações tanto das ações quanto dos sujeitos individuais e sociais a elas relacionadas, para simplificações do proposto ou, ainda, para leituras muito diversas do que é pretendido (FERRETI; ZIBAS; TARTUCE, 2004, p. 416).

Outra faceta do Protagonismo Juvenil relaciona-se à socialização cidadã que garante a coesão social, compreendida como atuação pontual de indivíduos ou grupos em ações sociais que buscam atender a problemas da sociedade contemporânea, por meio do voluntariado. No âmbito escolar trata-se de educar os estudantes para que exerçam uma cidadania responsável, compreendida como uma ação solidária, na perspectiva do desenvolvimento individual e social, incorporando a ideologia da neutralidade dos fatos sociais. Concepção questionada: "como se premissas 
políticas e ideológicas estivessem ausentes dessa ação proposta aos jovens". (FERRETTI, ZIBAS E TARTUCE, 2004, p. 419)

Essas formas de compreender o Protagonismo Juvenil se evidenciam nas normativas que institucionalizaram o Programa Ensino Integral.

A Lei Complementar $n^{\circ} 1.164$, de 4 de janeiro de 2012, no artigo $2^{\circ}$, considera:

I - Escolas Estaduais de Ensino Médio de Período Integral - unidades escolares de ensino médio de turno integral, que têm como objetivo a formação de indivíduos autônomos, solidários e produtivos, com conhecimentos, valores e competências dirigidas ao pleno desenvolvimento da pessoa humana e seu preparo para o exercício da cidadania, mediante conteúdo pedagógico, método didático e gestão curricular e administrativa próprios, conforme regulamentação, observada a Base Nacional Comum, nos termos da lei (SÃO PAULO, 2012a).

Já a Lei Complementar n 1.191, de 28 de dezembro de 2012, alterou o artigo 2, com a seguinte redação:

I - Ensino Integral - tem como objetivo a formação de indivíduos autônomos, solidários e competentes, com conhecimentos, valores e habilidades dirigidas ao pleno desenvolvimento da pessoa humana e seu preparo para o exercício da cidadania, mediante conteúdo pedagógico, método didático e gestão curricular e administrativa próprios, conforme regulamentação, observada a Base Nacional Comum, nos termos da lei, podendo o Ensino Integral ser oferecido em unidades escolares de ensino fundamental e/ou médio (SÃO PAULO, 2012C).

Nas normativas que institucionalizaram o Programa Ensino Integral foi omitida a disposição constitucional de "formação para o trabalho". Se concebermos o "trabalho" como ação consciente dos seres humanos na transformação da natureza e da sociedade, ou seja, "como práxis que possibilita criar e recriar, não apenas no plano econômico, mas no âmbito da arte e da cultura, linguagem e símbolos, o mundo humano como resposta as múltiplas e históricas necessidades" (FRIGOTTO, 2010, p.60), sua omissão sugere uma visão reducionista sobre a formação do cidadão no âmbito do Programa Ensino Integral.

A legislação evidencia a forma de Protagonismo Juvenil como aquele que promove a educação de habilidades e valores que favoreçam a 
adaptação dos jovens ao desenvolvimento econômico, apropriada à cultura gerencial, fragilizando o caráter histórico e democrático da educação.

\section{REFLEXÕES FINAIS}

A reforma administrativa da Secretaria Estadual de Educação do estado de São Paulo, orientada pelos processos de gerencialismo e gerencialização, reestruturou as formas de gerir a rede de ensino, com a ampliação dos processos de verticalização na tomada de decisões. A ausência de esferas de participação de pais, professores, estudantes, funcionários e diretores e demais especialistas na elaboração, acompanhamento e avaliação da política educacional da rede estadual de ensino, fere o princípio constitucional de gestão democrática do ensino público (CF, 1988, Art. 206, Inciso VI), comprometendo a qualidade do ensino ao distanciar do processo decisório, os principais sujeitos implicados na materialização do ensino escolar.

O estudo revelou que a rede estadual de ensino, de forma geral, comporta três tipos de atendimento: a) unidades escolares de tempo parcial; b) unidades escolares com ampliação da jornada para os estudantes com o "Projeto Escola de Tempo Integral"; e c) unidades escolares com as prerrogativas do Programa Ensino Integral, caracterizando uma oferta desigual para o conjunto de cidadãos paulistas, não atendendo ao princípio da "igualdade de condições para o acesso e permanência na escola" (Lei n 9.394/1996, Art. 3², Inciso I).

A análise dos processos de regulação do trabalho docente na rede estadual de ensino e, em especial, no Programa Ensino Integral, indicam a necessidade de ampliação da discussão sobre dois aspectos: financiamento e projeto político pedagógico.

Considerando o Programa Ensino Integral como uma referência para a análise sobre as condições de trabalho no âmbito da rede estadual de ensino, verificamos a necessidade urgente de aumento substancial de recursos financeiros a serem destinados exclusivamente para a rede estadual 
de ensino de São Paulo, pois, só assim será possível garantir a elevação do padrão de remuneração em $75 \%$ do valor da faixa e nível da Estrutura de Vencimentos de todos os gestores e docentes da rede estadual de ensino, bem como a adequação ao padrão da rede física das unidades escolares para o Ensino Integral, como também para adequação da Jornada de Trabalho de todos os professores da rede estadual de ensino para 0 exercício de sua função em uma única unidade escolar.

No âmbito do projeto político pedagógico torna-se imprescindível a discussão participativa sobre o significado do Protagonismo Juvenil que orienta o Programa de Ensino Integral, de forma a superar o caráter ahistórico e favorecer o trabalho docente que comporte o "pluralismo de ideias e de concepções pedagógicas" (CF, 1988, Art. 206, Inciso III).

As reformas educacionais implementadas na rede estadual de ensino do estado de São Paulo nas últimas duas décadas, incorporaram princípios neoliberais traduzidos no modelo de administração pública gerencial, com retórica descentralizadora e práticas centralizadoras nos processos decisórios, não favorecendo o aprendizado organizacional de todos os envolvidos, fundamental para a construção de um projeto democrático de educação.

\section{REFERÊNCIAS}

ABRUCIO, F. L. Trajetória recente da gestão pública brasileira: um balanço crítico e a renovação da agenda de reformas. Rev. Adm. Pública, Rio de Janeiro, v. 41, n. spe, p. 67-86, 2007. Disponível em http://www.scielo.br/scielo.php? script=sci_arttext\&pid=S0034$76122007000700005 \&$ lng=pt\&nm=iso. Acesso em 14 mai 2015.

\section{ADRIÃO, T. Educação e produtividade, a reforma do ensino paulista e a} desobrigação do Estado São Paulo: Xamã, 2006.

AZEVEDO, J. L. de. A educação como política pública Campinas, SP: Autores Associados, 1997.

BRASIL. Constituição da República Federativa do Brasil. Promulgada em 5 de outubro de 1988. Disponível em: http://goo.gl/O7mlEO. A cesso em: 12 abr. 2015. 
BRASIL. Lei $\mathbf{n}^{\circ}$ 9.394, de 20 de dezembro de 1996. Estabelece as diretrizes e bases da educação nacional. Disponível em: http://goo.gl/BMM7AO. Acesso em: 23 abr. 2015.

BRASIL (UNIÃO). EMENDA CONSTITUCIONAL N 19, de 4 de junho de 1998, Modifica o regime e dispõe sobre princípio e normas da Administração Pública, Servidores e Agentes polít icos, controle de despesas e finanças públicas e custeio de atividades a cargo do Distrito Federal, e dá outras providências. Disponível em: http://goo.gl/Gp4QCr. A cesso em: 20 abr. 2014.

CALLEGARI, C. (Org.) O FUNDEB e o financiamento da educação pública no

Estado de São Paulo 5a edição, São Paulo: A quariana; IBSA; APEOESP, 2010.

CASTRO, A. de; LOPES, R. E. A escola de tempo integral: desafios e possibilidades. Ensaio: aval. pol. públ. Educ., Rio de Janeiro, v. 19, n. 71, p. 259-282, jun. 2011. Disponível em http://goo.gl/44CN7E. Acesso em: 11 jul. 2015.

FA GNANI, E. "Política Social e Pactos Conservadores no Brasil: 1964/92" In Economia e Sociedade Campinas, n.8, p.183-238, jun. 1997.

FERRETTI, C. J.; ZIBAS, D. M. L.; TARTUCE, G. L. B. P. Protagonismo juvenil na literatura especializada e na reforma do ensino médio. Cad. Pesqui., São Paulo, v.34, n. 122, p. 411-423, ago. 2004 . Disponível em http://goo.gl/QZYxth. A cesso em: 19 abr. 2016.

FRIGOTTO, G. "Concepções e mudanças no mundo do trabalho e o ensino médio" In RAMOS, M., FRIGOTTO, G. e CIAVATTA, M. (Orgs.) Ensino Médio Integrado: concepção e contradições $2^{a}$ Edição, São Paulo: Cortez Editora, 2010.

HIPÓLITO, J. "A contratualização como instrumentação da acção pública" In BARROSO, J. e AFONSO, N. (Org.) Política Educativas: mobilização de conhecimento e modos de regulação. Portugal, Gaia: Fundação Manuel Leão, 2011.

HELOANI, José Roberto Montes e PIOLLI, Evaldo "Gerencialismo, Trabalho e Desumanização: alguns apontament os sobre o sofrimento e o adoecimento na docência" In Revista da APASE, São Paulo, Ano XI, n 13, maio de 2012.

KRAWCZYK, N. Ensino médio: empresários dão as cartas na escola pública. Educ. Soc., Campinas, v. 35, n. 126, p. 21-41, mar. 2014. Disponível em http://goo.gl/a7m32F. Acesso em: 16 mar. 2016.

MAGUIRE, M.; BALL, S. J. "Discursos de reforma educacional no Reino Unido e nos Estados Unidos e o trabalho dos professores" In BALL, S. J. ; MAINARDES, J. Políticas Educacionais: questões e dilemas São Paulo: Cortez, 2011. 
NEWMAN, J; CLARKE, J. Gerencialismo. Educ. Real., Porto Alegre, v. 37, n. 2, p. 353-381, ago. 2012. Disponível em https://goo.gl/LmkXiL. Acesso em 07 mai 2014.

OLIVEIRA, C. e GANZELI, P. "O processo de municipalização do ensino fundamental, da primeira à quarta série, em Piracicaba" In GIUBILEI, S. (Org.) Descentralização, Municipalização e Políticas Educativas Campinas, SP: Alínea, 2001.

PEREIRA, L. C. B. "Gestão do setor público: estratégia e estrutura para um novo Estado" In PEREIRA, L. C. B. e SPINK, P. K. (Orgs.) Reforma do Estado e administração pública gerencial $3^{\circ}$ edição, Rio de Janeiro: Editora FGV, 1999.

PINTO, J. M. de R. A política recente de fundos para o financiamento da educação e seus efeit os no pacto federativo. Educ. Soc., Campinas, v. 28, n. 100, p. 877-897, out. 2007. Disponível em: http://twixar.me/pdQK. A cesso em: 04 maio 2010.

SÃO PAULO (ESTADO) Lei Complementar Nº 444, de 27 de dezembro de 1985 , Dispõe sobre o Estatuto do Magistério Paulista e dá providências correlatas. Disponível em: http://goo.gl/6xuZmE. Acesso em: 19 de abr. 2016.

SÃO PAULO (ESTADO) Secretaria da Educação Resolução n 89, de 09 de dezembro de 2005, "dispõe sobre o Projeto de Escola de Tempo Integral". Disponível em: http://goo.gl/gq7qTE. A cesso em: 05 de mar. 2016.

SÃO PAULO (ESTADO) Lei Complementar $n^{\circ}$ 1.078, de 17 de dezembro de 2008, Institui Bonificação por Resultados - BR, no âmbito da Secretaria da Educação. Disponível em: <http://goo.gl/o65PSU>. A cesso em: 07 de abr. 2016.

SÃO PAULO (ESTADO) Decreto N 57.141, de 19 de junho de 2011, reorganiza a Secretaria da Educação e dá providências correlatas. Disponível em: http://goo.gl/5BCQOt. Acesso em: 19 abr. de 2016.

SÃO PAULO (ESTADO) Secretaria da Educação Lei Complementar $\mathbf{n}^{\circ} \mathbf{1 . 1 6 4}$, de 04 de janeiro de $2012 a$, Institui o Regime de dedicação plena e integral RDPI e a Gratificação de dedicação plena e integral - GDPI aos integrantes do quadro do Magistério em exercício nas escolas estaduais de ensino médio de período integral, e dá providências correlatas. Disponível em: http://goo.gl/n8zl75. Acesso em: 20 ago. de 2015.

SÃO PAULO (ESTADO) Secretaria da Educação, Resolução n 08, de 19 de janeiro de 2012b, Dispõe sobre a carga horária dos docentes da rede estadual de ensino, Disponível em: http://goo.gl/KoubQf. Acesso em: 23 abr. de 2016.

SÃO PAULO (ESTADO) Secretaria da Educação Lei Complementar $\mathbf{n}^{\circ} \mathbf{1 . 1 9 1}$ de 28 de dezembro de 2012c, Dispõe sobre o Programa Ensino Integral em 
escolas públicas estaduais e altera a Lei Complementar $n^{\circ} 1.164$, de 2012, que instituiu o Regime de dedicação plena e integral - RDPI e a Gratificação de dedicação plena e integral - GDPI aos integrantes do Quadro do Magistério em exercício nas escolas estaduais de ensino médio de período integral, e dá providências correlatas. Disponível em: http://goo.gl/ndTDND. Acesso em: 20 ago. de 2015.

SÃO PAULO (ESTADO) Secretaria da Educação A nova estrutura Administrativa da Secretaria da Educação do Estado de São Paulo: por uma gestão de resultado com foco no desempenho do aluno São Paulo, Secretaria da Educação; coordenação e execução, Sebastião Aguiar; edição final, Cesar Mucio Silva. São Paulo: SE, 2013.

SEGATTO, C. I.; ABRICCIO, F. L. "A gestão por resultados na educação em quatro estados brasileiros" In Ver. Serv. Público Brasília, 68 (1) 85-106, jan/mar 2017. Disponível em https://goo.gl/DMFqMJ. A cesso em 20 jun 2017.

SHIROMA, E. O., CAMPOS, R. F.; GARCIA, R.M. C. Decifrar textos para compreender a política: subsídios teórico-metodológicos para análise de documentos. Perspectiva, Florianópolis, v. 23, n. 2, p. 427-446, jan. 2005. ISSN 2175-795X. Disponível em: http://twixar.me/xdQK. Acesso em: 02 mai 2014.

SILVA, R. N. da "A Gestão Educacional no Estado de São Paulo" In Seminário Internacional Reformas de la Gestion de los Sistemas Educativos en la Decada de los Noventa. Santiago, Chile: UNESCO: Oficina Regional de Educacioón para América Latina y el Caribe; IX Seminario-Taller Regional de Políticas y Gestion Educativas, 10 a 18 de noviembre de 1997.

Recebido em: 14 de fevereiro de 2019.

Aprovado em: 30 de maio de 2019. 